\title{
Decision Support System for Designing Effective Noise Hazard Prevention Strategies
}

\author{
Krisada Asawarungsaengkul \\ Suebsak Nanthavanij \\ Junalux Chalidabhongse
}

Sirindhorn International Institute of Technology, Thammasat University, Pathum Thani, Thailand

A decision support system for designing effective noise hazard prevention (NHP) strategies is proposed. NHP consists of four modules: (a) database, (b) input, (c) algorithms, and (d) solution. The user can choose among single-, two-, and three-approach solution procedures. Heuristic and genetic algorithms are used to determine appropriate noise controls (NCs). From the given noise condition and NC budget, NHP recommends a minimum-cost NHP strategy that prevents any worker's daily noise exposure from exceeding the permissible level. If the budget is insufficient, NHP is able to search for a feasible noise hazard strategy that requires a minimum NC budget. decision support system noise hazard prevention genetic algorithms noise control

\section{INTRODUCTION}

Repetitive prolonged exposure to loud noise is a leading cause of hearing loss. Noiseinduced hearing loss is one of the most common occupational diseases. A major cause of this disease is lack of an effective noise hazard prevention (NHP) strategy in the workplace.

Most ergonomics and safety engineering textbooks generally recommend three approaches to NHP. They are (a) an engineering approach, (b) an administrative approach, and (c) the use of hearing protection devices (HPDs). The engineering approach includes procedures that reduce the sound level either at the noise source or within the hearing zone of the workers. This approach is more heavily emphasized than the others, due to its high effectiveness in noise reduction. Their details can be found in noiserelated literature $[1,2,3,4,5,6]$.
Detailed discussions on the administrative approach are relatively scarce. Job rotation, a practical management technique to reduce workers' exposure to loud noise, is usually recommended. To implement job rotation, it is necessary to generate daily work assignments for workers (i.e., where they have to work in each work period). Nanthavanij and Yenradee [7] developed a minimax work assignment model to determine optimal work assignments for workers so that the maximum daily noise exposure that any worker receives is minimized. For large-sized job rotation problems, genetic algorithms were developed to determine near-optimal minimax work assignments [8, 9]. Yaoyuenyong and Nanthavanij [10] also developed a simple heuristic for solving large minimax work assignment problems. For workplaces where noise levels are excessively high, Nanthavanij and Yenradee [11] recommended that the number of workers be greater than the number of machines/workstations 
that need attention. They also developed a mathematical model to determine the minimum number of workers so that their daily noise exposures do not exceed permissible levels.

Harris [1], Beranek and Vér [2], Cheremisinoff [3], Ridley [4], and Wilson [5] have discussed various types of HPDs and their properties. In addition, Behar and Kunov [12]; Crabtree and Behar [13]; Birch, Gerges, and Vergara [14]; and Buchweiller, Mayer, Klein, et al. [15] have reported research studies on the development and testing of effective HPDs. Workers' resistance to HPDs has also been discussed [16].

According to the U.S. Occupational Safety and Health Administration (OSHA), the workplace where any worker's daily noise exposure exceeds $90 \mathrm{dBA}$ is required to have an NHP strategy implemented [17]. The current Labor Protection Act in Thailand also sets the permissible daily noise exposure limit at $90 \mathrm{~dB} A$ and requires employers to implement an appropriate hearing conservation program if a worker's daily noise exposure exceeds this limit. Specifically, engineering controls are to be considered first. If they are not feasible, administrative controls such as job rotation should be considered next. The use of HPDs is specified as the last resort of noise exposure reduction. They should be applied only when engineering and administrative controls fail to prevent daily noise exposures from exceeding the permissible level. HPDs should be used to assist, not to replace, engineering and administrative controls. However, employers often choose not to follow OSHA's hierarchy of noise control (NC) due to a large capital investment that is normally required for engineering controls and the difficulty in implementing engineering and administrative controls. As a result, only HPDs (earplugs, earmuffs, etc.) are often provided to workers as a means for NHP.

Sanders and McCormick [18] have recommended that a combination of NCs (from the three approaches) be applied concurrently to achieve the desired level of abatement. However, finding an appropriate combination of NCs is usually difficult especially when requirements such as NC budget and permissible noise level need to be simultaneously satisfied. Sutton [19] has presented a procedure to identify possible methods of noise reduction and to select the best method using a cost/benefit analysis. Asawarungsaengkul and Nanthavanij [20] have developed an analytical procedure that sequentially solves a series of mathematical models to yield an optimal NHP solution based on a given budget. However, their approach requires long computation time and may not yield the solution when the size of the NC problem becomes large.

In the past years, a number of decision support systems (DSSs) have been developed to assist management, industrial engineers, and management scientists in decision making. Due to their interactive and computerized nature, most DSS programs are relatively easy to use and are able to generate management solutions that suit the preference of decision-makers. Areas of application of DSSs range from human resource management to risk management to engineering. Examples of DSS applications that were developed to deal with human resource management include productivity improvement [21], performance analysis [22], and employeejob assignment [23]. A computer-based system for risk management was presented by Peckham, Haastrup, and Otway [24], whereas a DSS for risk assessment was developed by Gheorghe, Mock, and Kröger [25]. Hanss [26] has discussed the use of DSSs in engineering management. Parker, Malstrom, Irwin, et al. [27] developed a DSS for scheduling technical personnel. Various DSSs in the industrial engineering field have been discussed [28, 29, 30, 31, 32]. However, to our knowledge, a DSS for NHP has never been developed.

In this paper, a DSS for designing effective NHP strategies based on a given noise condition, preferred solution procedure, and NC budget is proposed. In section 2, we briefly discuss the three NC approaches. In section 3, the design of NHP and its four modules is described in detail. An NHP example is given in section 4, from which seven strategies are evaluated. NHP is then used to generate minimum-cost NHP solutions for the seven NHP strategies (section 5). We 
finally conclude the findings of this research in section 6 .

\section{NC APPROACHES}

Generally, there are three approaches for NC, namely, an engineering approach, an administrative approach, and the use of HPDs.

\subsection{Engineering Approach}

As stated earlier, an engineering approach includes procedures that reduce the sound level either at the noise source or within the workers' hearing zone. Examples of common engineering controls are as follows [33]:

- maintenance;

- substitution of machines;

- substitution of processes;

- reduction of the driving force of vibrating surfaces;

- reduction of the response of vibrating surfaces;

- reduction of the sound radiation from vibrating surfaces;

- reduction of the sound transmission through solids;

- reduction of the sound produced by gas flow; and

- reduction of noise by reducing its transmission through air.

Alternatively, engineering controls can be categorized as those that are applied at the noise source and those that are applied to block the noise transmission path. Reduction of the noise level at its source will cause noise levels at all worker locations to be reduced. On the other hand, blocking the noise transmission path will only affect the worker location (or locations) that is located along a straight path.

\subsection{Administrative Approach}

Administrative controls are management procedures to reduce the duration of exposure to noise rather than to reduce the noise level. Examples of administrative controls are as follows [33, 34, 35]:
- rotating workers from a high- to a low-noise location so that their daily noise exposures are reduced;

- transferring workers who are particularly susceptible to noise to work in a less noisy work area;

- allowing workers to take shift brakes in a quiet rest area;

- changing production schedules so that exposure times to loud noise are reduced; and

- interrupting production runs with preventive maintenance to give workers quiet time.

When job rotation is implemented, it is common to use the same number of workers as the number of worker locations. However, if workplace noise is excessive, it is necessary to have more workers than worker locations so that some workers are idle (and, subsequently, not exposed to loud noise) in some work periods.

\subsection{Use of HPDs}

The use of HPDs to reduce noise exposure should not be applied unless noise reduction through engineering and administrative controls is ineffective or has reached its limits. There are two basic types of HPDs: passive and active. Passive HPDs are the most common in industry, and include conventional earplugs, ear canal caps, and earmuffs. Active HPDs are earplugs, canal caps, earmuffs, or even noise-attenuating helmets that incorporate electronic components and transducers. They provide active noise reduction, communications features, and attenuation, which are level-dependent. They reduce noise by introducing destructive cancellation by applying opposite-phase sound waves at the ears.

\section{DECISION SUPPORT SYSTEM FOR NHP}

A DSS for NHP has been developed on MSAccess version 2003 using Visual Basic for Application (VBA) version 2003. NHP consists of four modules, namely, database, input, algorithms, and solution. The database module stores information on machines, engineering controls, and HPDs. The input module provides 
a user-friendly interface to assist the user in inputting additional data and choosing a preferred solution procedure. Users may choose OSHA's hierarchy of NC or any built-in solution procedure based on their preference. The algorithms module utilizes heuristic and genetic algorithms to generate a near-optimal NHP strategy according to a given $\mathrm{NC}$ budget and the chosen solution procedure. Finally, the solution module presents a report that shows the recommended NCs and the resulting daily noise exposures of all workers.

\subsection{The Database Module}

The database module is a master setup module of NHP. Its function is to construct a database of machines, engineering noise reduction (at the source), engineering noise reduction (along the path) or noise barrier, and HPDs. The user is required to firstly enter relevant information on the workplace into the database before visiting the other three modules. Table 1 shows the four categories of workplace data that must be entered into the database of an NHP program.

TABLE 1. Workplace Data Stored in the NHP Strategies Database

\begin{tabular}{|c|c|}
\hline Category & Required Information \\
\hline Machine data & $\begin{array}{l}\text { machine ID } \\
\text { machine type/description } \\
\text { machine noise level }(\mathrm{dB} A)\end{array}$ \\
\hline $\begin{array}{l}\text { Engineering NRS } \\
\text { data }\end{array}$ & $\begin{array}{c}\text { NRS ID } \\
\text { NRS description }\end{array}$ \\
\hline Noise barrier data & $\begin{array}{c}\text { noise barrier ID } \\
\text { noise barrier type/description }\end{array}$ \\
\hline HPD data & $\begin{array}{c}\text { HPD ID } \\
\text { HPD type/description } \\
\text { HPD cost }\end{array}$ \\
\hline
\end{tabular}

Notes. NHP-noise hazard prevention, IDidentification, NRS - noise reduction at the source, HPD—hearing protection device.

\subsection{The Input Module}

The input module enables the user to create an $\mathrm{NC}$ project. Each NC project is basically an NC problem. For a given workplace, the user may create several NC projects, depending on the size and scope of the project. Firstly, relevant information can be retrieved from the NHP database. Next, additional necessary data such as machine locations, worker locations, applicable
NC measures (for each noise source), costs, and $\mathrm{NC}$ budget will be entered. Following are the steps that the user usually performs when creating an NC project.

1. The user must define an NC project either by creating a completely new $\mathrm{NC}$ project or retrieving any of the existing $\mathrm{NC}$ projects. If a new NC project is to be created, the user must enter the project ID, project name and description, total NC budget (TB), and HPD budget (HB).

2. The user has to retrieve relevant machines from the database to be included in the $\mathrm{NC}$ project. For each machine, the user also needs to specify its location co-ordinates $(x, y)$. It is assumed that the level height of the machine noise source is at or near the human ear's level; thus, the $z$ co-ordinate of the machine may be neglected.

3. Noise-reduction-at-the-source (NRS) techniques (to be retrieved from the database) can be defined for each selected machine. For a machine, it is possible to have several NRS techniques that can be applied to reduce machine noise. It is also necessary to define noise reduction rating (NRR), in $\mathrm{dB} A$, and the cost of each NRS technique.

4. All location co-ordinates of worker locations are then defined.

5. If controlling noise along the path can be applied, the user can retrieve the noise barriers (including their ID and description) from the database. For noise barrier cost and NRR, the user has to enter the data in this step.

6. If the number of available workers to be included in the $\mathrm{NC}$ project is greater than the number of worker locations, this can be specified in this step.

7. The last step is to select the HPDs to be used in the NC project. Again, HPD data can be retrieved from the database.

\subsection{The Algorithms Module}

The main function of the algorithms module is to perform necessary computations based on a 
prespecified solution procedure and to determine the resulting noise exposures of all workers.

Consider a workplace where workers are present at various locations during an $8-\mathrm{hr}$ workday. Since there are usually several noise sources and workers may not stay at one location, it is necessary to determine an 8-hr timeweighted average (8-hr TWA) sound level that each worker receives (i.e., daily noise exposure). Letting $C_{j}$ and $\bar{L}_{j}$ be exposure duration (in hours) and combined noise level (in $\mathrm{dBA}$ ), respectively, at worker location $j$, a formula to determine an 8-hr TWA that worker $i$ receives, $W_{i}$, is

$$
W_{i}=16.61\left[\log _{10}\left\{\sum_{j=1}^{n} \frac{C_{j}}{8}\left(2^{\frac{\bar{L}_{j}-90}{5}}\right)\right\}\right]+90 \text {. }
$$

By dividing an 8-hr workday into $p$ equal work periods, its noise weight per work period can be determined from $\bar{L}_{j}$ :

$$
w_{j}=\frac{1}{p} \times 2^{\left(\frac{\bar{L}_{j}-90}{5}\right)} .
$$

To prevent daily noise exposure from exceeding $90 \mathrm{~dB} A$, the total noise weight that any worker receives within an 8-hr workday must not be greater than 1 .

\subsubsection{Algorithms for engineering controls}

Both controlling at the noise source and controlling along the noise transmission path are considered engineering controls. The former implies that machine noise is reduced and all worker locations will benefit from such noise reduction. The latter, however, will reduce the noise level at some worker locations (only those where the noise barrier can block the noise transmission path).

From the available engineering NCs, the selection of appropriate controls can be formulated as cost- and safety-based models [36]. The cost-based model is intended to minimize the total cost when feasible engineering controls are applied so that the combined noise level at any worker location does not exceed $90 \mathrm{~dB}$. The safety-based model, on the other hand, is intended to minimize the maximum noise weight per work period among all worker locations such that the resulting total cost does not exceed the allocated engineering control budget (EB).

To enhance the practicality of NHP strategies, genetic algorithms (GAs) of cost- and safetybased models are used instead of mathematical models. For more details on a GA approach to the selection of engineering $\mathrm{NCs}$, see Asawarungsaengkul and Nanthavanij [37].

\subsubsection{Algorithms for an administrative approach}

The only administrative control considered in NHP is an application of job rotation to rotate workers among worker locations so that the maximum daily noise exposure that any worker receives does not exceed $90 \mathrm{~dB}$. Workers are allowed to rotate to another worker location only at the end of the work period.

Two mathematical models have been developed for job rotation [36]. The first model determines a set of feasible work assignments for the current workforce such that the total worker-location changeover is minimized. The worker-location changeover occurs when a worker moves from one worker location to another. To some extent, productivity might be affected due to learning of and adapting to a new task. Thus, it is necessary to keep the number of worker-location changeovers as low as possible.

Let $x_{i, j, k}$ be a $(0,1)$ binary variable such that $x_{i, j, k}=1$ if worker $i$ is assigned to worker location $j$ in work period $k$, and $x_{i, j, k}=0$ otherwise. At worker location $j$, the formula to determine the number of worker-location changeovers $f_{j}$ is

$$
f_{j}=\sum_{k=1}^{p-1}\left[1-\sum_{i=1}^{m}\left(x_{i, j, k} \times x_{i, j, k+1}\right)\right],
$$

where $j=1, \ldots, n ; m$-number of workers, $n$-number of worker locations, and $p$-number of work periods.

For all $n$ locations, the total worker-location changeover $F$ is

$$
F=\sum_{j=1}^{n} \sum_{k=1}^{p-1}\left[1-\sum_{i=1}^{m}\left(x_{i j k} \times x_{i, j, k+1}\right)\right] .
$$

The second mathematical model considers the situation in which additional workers are required 
for job rotation due to excessive noise levels in the workplace. The objective is to determine the minimum number of workers (in the workforce) to be rotated among the given worker locations such that none of the workers receives daily noise exposure beyond $90 \mathrm{~dB} A$ [36].

Job rotation models do not consider costs since job rotation does not require any equipment investment or workplace modification. It is assumed that any incurred costs due to a decline in productivity will be absorbed by the production department. For a case in which more workers are needed for job rotation, it is also assumed that they are existing workers (perhaps from other departments), not new workers. If job training is provided, the training cost will be absorbed by the human resources department.

To implement job rotation, the following assumptions are required.

1. maximum working time (for workers and machines) per day is $8 \mathrm{hrs}$;

2. a workday can be divided into $p$ equal periods; job rotation occurs at the end of the work period;

3. each worker location requires only one worker to attend per work period;

4. each worker can attend only one worker location per work period; and

5. workers' efficiency is independent of the task they are assigned to perform. Similarly, task output is independent of the worker.

Like in the selection of engineering NCs, GAs of the job rotation models are used instead of mathematical models. Yaoyuenyong and Nanthavanij's [38] hybrid procedure is firstly used to generate an initial population. Then, the heuristic GA is applied to determine the work assignment solution (for more details, see Asawarungsaengkul and Nanthavanij [39]).

\subsubsection{Algorithms for the use of HPDs}

When using HPDs as a means for NHP, it is recommended that the number of worker locations where HPDs are required be as low as possible. In practice, HPDs should be worn only at very noisy worker locations.
Two mathematical models for selecting appropriate HPDs have been developed [37]. Both models consider job rotation and the use of HPDs concurrently. The first model determines the minimum number of HPDs based on a given HPD budget (HB) and the current workforce. The model also yields the type of HPDs and worker location where HPDs must be worn. The second model determines the minimum number of HPDs when the current workforce and additional workers are considered for job rotation.

GAs for job rotation discussed in section 3.3.2. can be utilized in conjunction with a heuristic to select the minimum number of HPDs. In brief, the computation comprises two phases: (a) to find the minimum number of HPDs, and (b) to find optimal work assignments. They are described as follows.

\subsubsection{Phase 1: Find the minimum number of}

HPDs. The heuristic consists of seven steps.

1. Rank all HPDs in descending order of their cost. A more expensive HPD must also have a higher NRR. Otherwise, it will be eliminated from the HPD list.

2. Rank all worker locations in descending order of the combined noise level.

3. Start at node level $=1$ (at a worker location with the highest combined noise level). All available HPDs from step 1 are considered, forming branches of nodes. The number of nodes is equal to the number of HPDs in step 1.

4. Calculate the total HPD cost and the lower bound of the required number of workers for each branch. The computation of the lower bound can be found in Yaoyuenyong and Nanthavanij [38]. The branch with the total HPD cost greater than HB is bounded. If there is a branch that has the lowest lower bound, its total HPD cost not exceeding HB, and the lower bound not exceeding the available number of workers, go to step 5. Otherwise, go to step 6.

5. Calculate new $w_{j}$ for all worker locations and apply Yaoyuenyong and Nanthavanij's [38] heuristic to find the minimum number of workers. If the number of workers does not 
exceed the available workforce, go to step 7. Otherwise, go to step 6.

6. Set level $=$ level +1 . At level $>1$, nodes can be branched from the parent node until the number of nodes is equal to the number of available HPDs (excluding HPDs already eliminated in step 1). After that, return to step 4.

7. Set the number of HPDs required for NC equal to level and stop the procedure. The branch with the minimum total HPD cost will be chosen.

\subsubsection{Phase 2: Find optimal work assignments.}

From the HPDs and worker locations chosen in phase 1 , calculate new $w_{j}$ for all $j$ s. Then, apply the GA from section 3.3.2. to find the minimum total worker-location changeover.

\subsubsection{Solution procedures}

NHP has three built-in solution procedures. The first and second procedures contain three suboptions:
1. the single-approach procedure: (a) engineering controls, (b) job rotation, (c) the use of HPDs;

2. the two-approach procedure: (a) engineering controls-then-job rotation, (b) engineering controls-then-HPDs, (c) job rotation-thenHPDs; and

3. the three-approach procedure, for which OSHA's hierarchy of control is followed.

Figures 1,2, and 3 illustrate the three procedures. If the NC budget is insufficient, the algorithms module will search for a feasible NHP strategy with the minimum total cost and recommend its total cost as the revised NC budget. In Figures 1, 2 , and 3 , option $=1$ means job rotation involving only the existing workers and option $=2$ means job rotation with additional workers. Also, EB and $\mathrm{NH}$ (number of HPDs) represent the engineering control budget and the number of hearing protection devices, respectively.

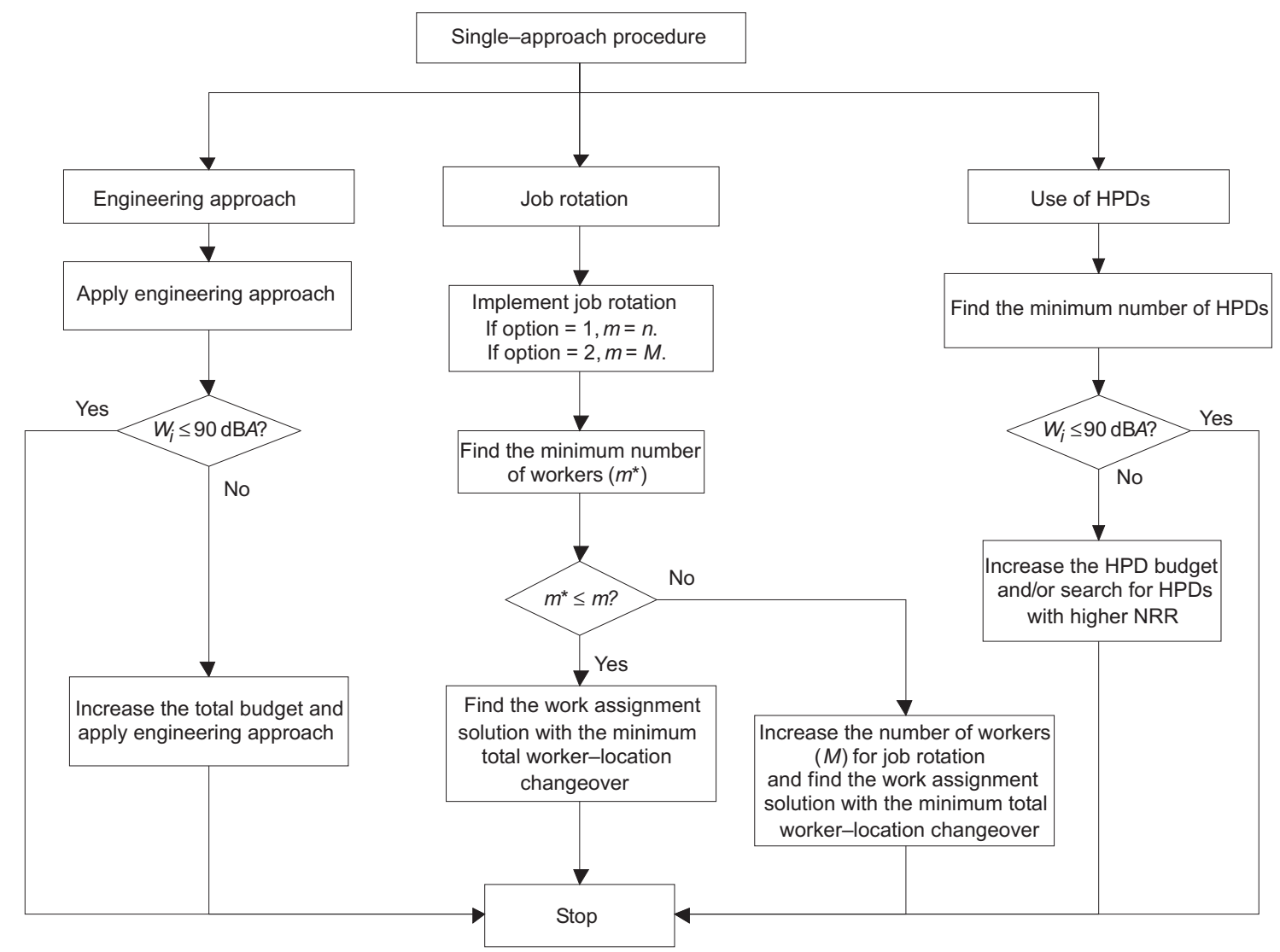

Figure 1. The single-approach procedure. Notes. HPDs-hearing protection devices, NRR-noise reduction rating. 


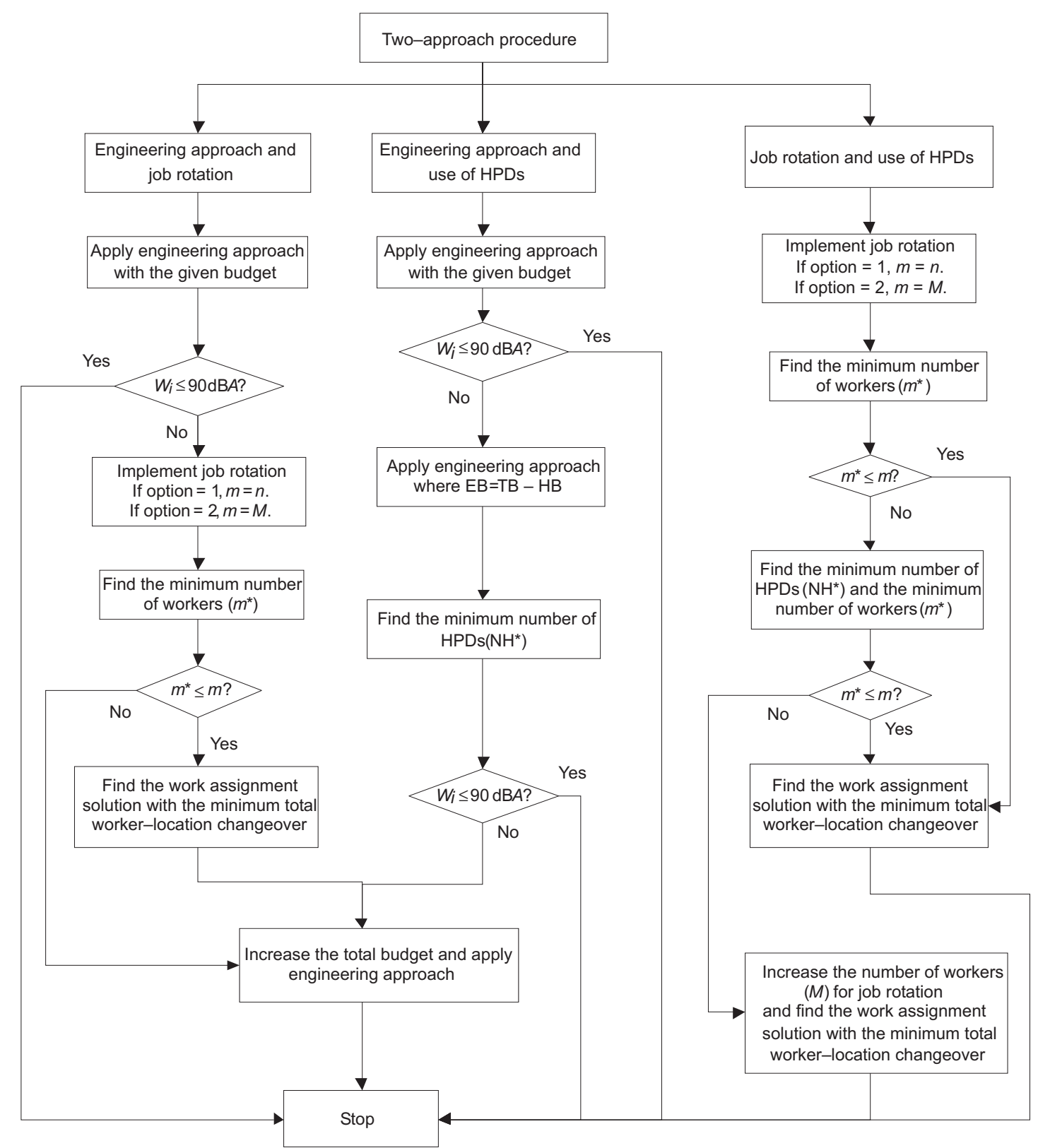

Figure 2. The two-approach procedure. Notes. HPDs-hearing protection devices, EB-engineering control budget, TB-total noise control budget, $\mathrm{HB}$ - budget of hearing protection devices, $\mathrm{NH}$-number of HPDs. 


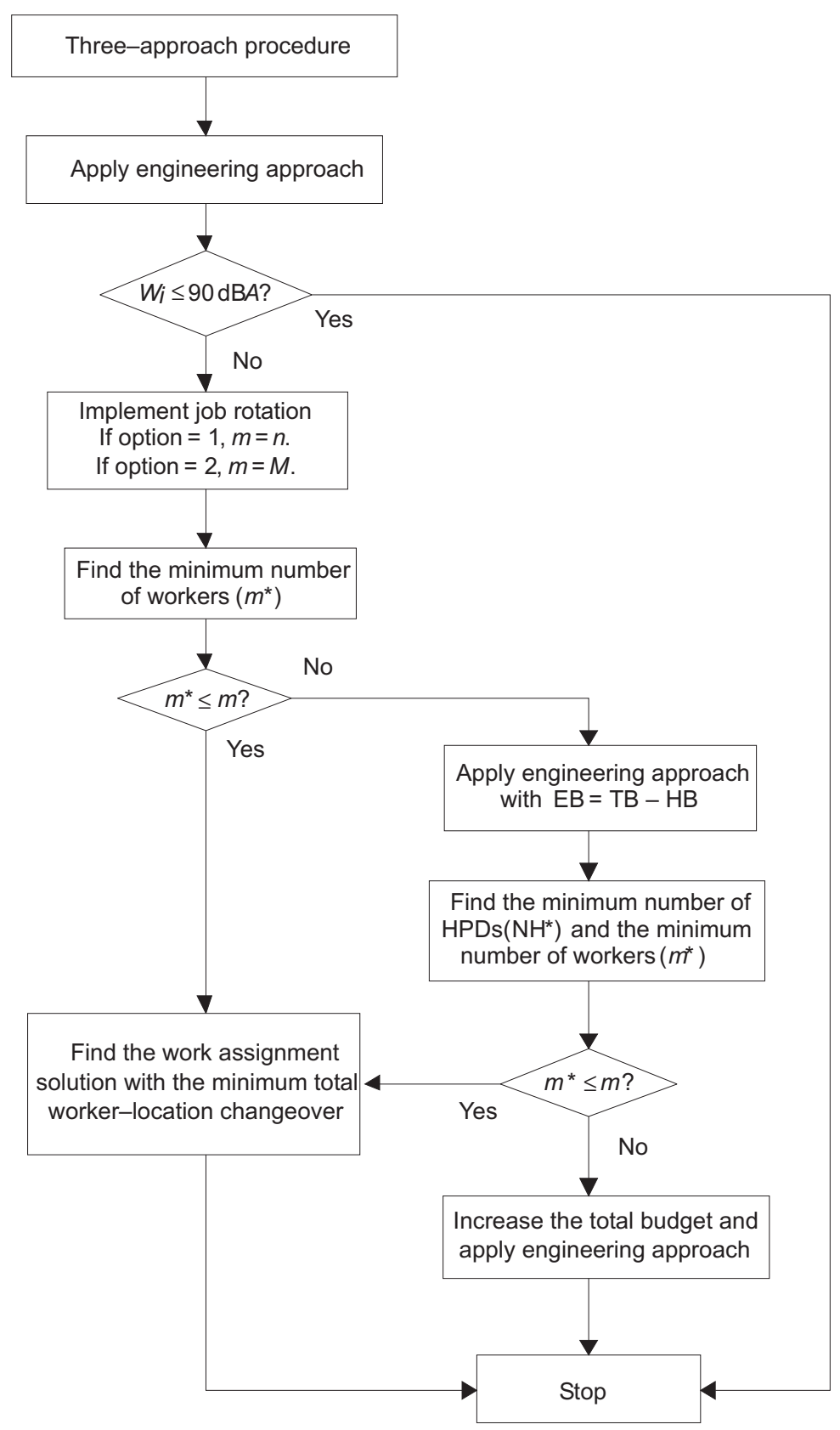

Figure 3. The three-approach procedure. Notes. HPDs—hearing protection devices, EB-engineering control budget, TB—total noise control budget, $\mathrm{HB}$ - budget of hearing protection devices, $\mathrm{NH}-$ number of HPDs.

\subsection{The Solution Module}

After obtaining an NHP strategy based on the given $\mathrm{NC}$ budget and the preferred solution procedure, NHP will generate a report using the solution module. The details of the NHP solution report depend on the NCs chosen in the algorithms module, and can be summarized as follows:
- daily noise exposures of individual workers (before NHP);

- recommended NCs (as chosen in the input module): (a) noise reduction at the source, (b) noise barrier, (c) job rotation (using current workforce), (d) job rotation (using available workforce), (e) required HPD for each worker location;

- resulting work assignments; 
- daily noise exposures of individual workers (after NHP).

The solution module also generates an electronic output file for each NC project. If an NHP strategy cannot be found, a feasible NHP strategy with an increased budget (if engineering controls are to be applied) or an increased number of workers (if job rotation is to be implemented) will also be presented in the output file. A flow chart of NHP is shown in Figure 4.

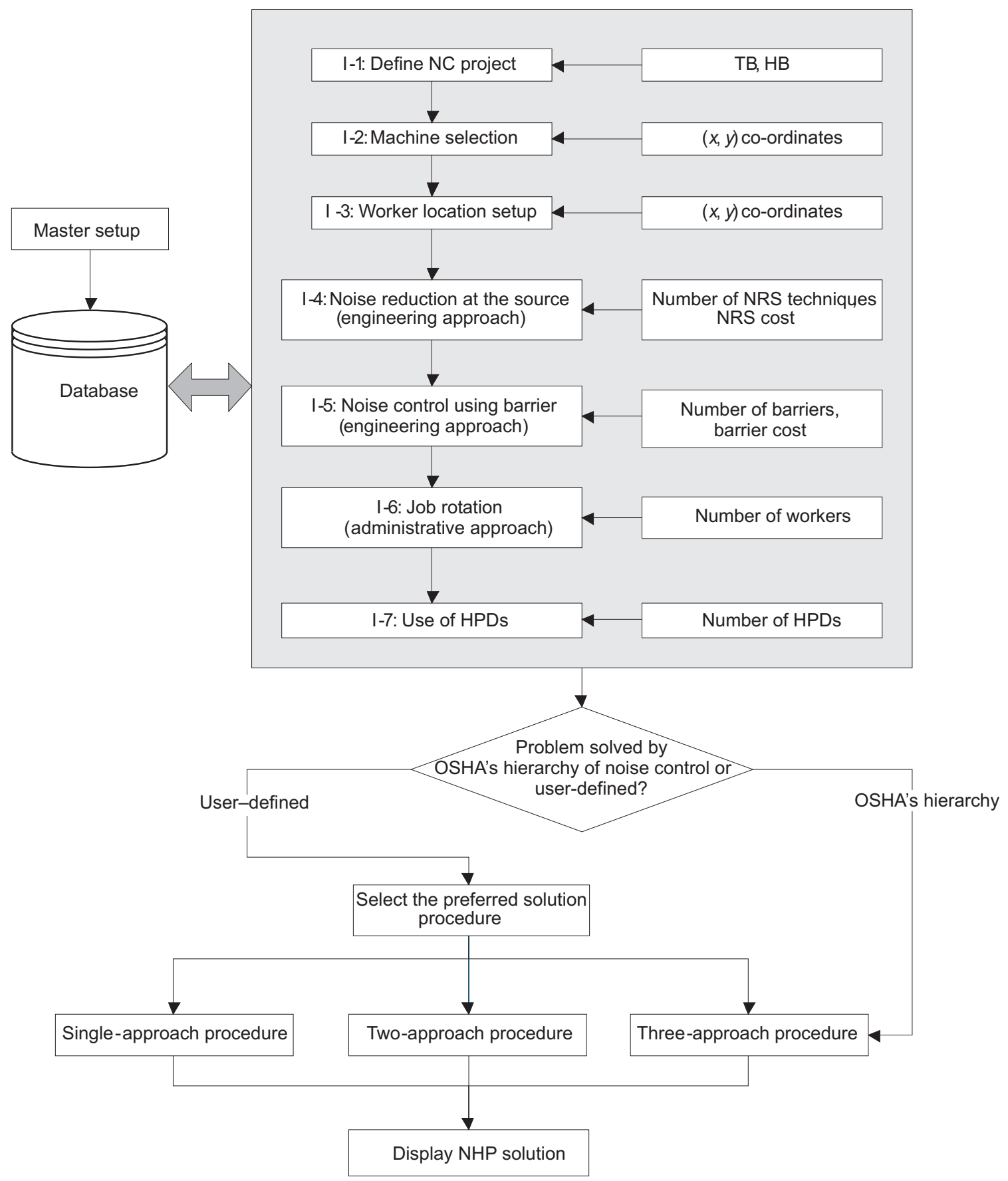

Figure 4. Noise hazard prevention (NHP). Notes. NC-noise control, TB-total noise control budget, $\mathrm{HB}$-budget of hearing protection devices, NRS - noise reduction at the source, HPDs-hearing protection devices, OSHA-Occupational Safety and Health Administration (USA). 


\section{NHP EXAMPLE}

Consider a production facility with eight machines (M1, M2, .., M8). Presently, there are six workers $(\mathrm{W} 1, \mathrm{~W} 2, \ldots, \mathrm{W} 6)$ assigned to six worker locations (WL1, WL2, ..., WL6). Background noise level is $70 \mathrm{dBA}$. Table 2 shows location co-ordinates of the eight machines, their noise levels, and location co-ordinates of the six worker locations. The machine noise level is a sound pressure level measured $1 \mathrm{~m}$ from the machine noise source.

From the given machine noise data, the combined noise levels at the six worker locations are 91.59, 92.37, 91.82, 91.29, 91.68, and $91.31 \mathrm{~dB} A$, respectively. If each worker is assigned to one worker location and job rotation is not implemented, it is obvious that all six workers are exposed to noise hazard since their daily noise exposures exceed the permissible level. An effective NHP strategy is required to reduce their daily noise exposures. To implement job rotation, an 8-hr workday is divided into four equal work periods. If necessary, two additional workers can be assigned to work in this facility.

Table 3 shows two engineering controls for reducing machine noise at individual machines, costs, and noise reduction levels. Furthermore, there are two types of noise barriers for blocking the noise transmission path. Type-1 noise barrier costs 15000 baht (US \$375) and reduces noise levels at worker locations WL1 and WL3 by 4 and $8 \mathrm{~dB} A$, respectively. Type-2 barrier also costs 15000 baht (US \$375). It reduces noise levels at worker locations WL2 and WL6 by 4 and $8 \mathrm{~dB} A$, respectively. There are two types of HPDs, type-A and type-B, which can be worn at any of the six worker locations. A type-A HPD costs 100 baht (US \$2.50) and its effective NRR is $8 \mathrm{~dB} A$. A type-B HPD costs 500 baht (US \$12.50), with an effective NRR of $12 \mathrm{~dB} A$.

Management has set the total $\mathrm{NC}$ budget at 30000 baht (US \$750), with the budget for HPDs at 1000 baht (US \$25). NHP is used to design an

TABLE 2. Machine Location Co-Ordinates, Noise Levels, and Worker Location Co-Ordinates

\begin{tabular}{lrrrrrr}
\hline & \multicolumn{2}{c}{ Location Co-Ordinate $(\mathbf{m})$} & & \multicolumn{3}{c}{ Location Co-Ordinate $(\mathbf{m})$} \\
\cline { 2 - 3 } Machine & $\boldsymbol{x}$ & $\boldsymbol{y}$ & Machine Noise (dBA) & Worker Location & $\boldsymbol{x}$ & $\boldsymbol{y}$ \\
\hline M1 & 3 & 3 & 94 & WL1 & 3 & 4.5 \\
M2 & 6 & 3 & 85 & WL2 & 12 & 4.5 \\
M3 & 9 & 3 & 88 & WL3 & 3 & 7.5 \\
M4 & 12 & 3 & 95 & WL4 & 6 & 7.5 \\
M5 & 3 & 9 & 94 & WL5 & 9 & 7.5 \\
M6 & 6 & 9 & 92 & WL6 & 12 & 7.5 \\
M7 & 9 & 9 & 93 & & & \\
M8 & 12 & 9 & 93 & & & \\
\hline
\end{tabular}

TABLE 3. Techniques for Reducing Machine Noise, Costs, and Noise Reduction

\begin{tabular}{lcccc}
\hline & \multicolumn{2}{c}{ NRS Technique 1 } & \multicolumn{2}{c}{ NRS Technique 2 } \\
\cline { 2 - 5 } Machine & Cost (baht) & Noise Reduction (dBA) & Cost (baht) & Noise Reduction (dBA) \\
\hline M1 & 6000 & 10 & 12000 & 12 \\
M2 & 7500 & 8 & - & - \\
M3 & 7500 & 8 & - & - \\
M4 & 9000 & 9 & 16000 & 15 \\
M5 & 9500 & 10 & 14500 & 13 \\
M6 & 10000 & 8 & 18000 & 12 \\
M7 & 11000 & 12 & 15000 & 15 \\
M8 & 8000 & 7 & 13000 & 11 \\
\hline
\end{tabular}

Notes. NRS - noise reduction at the source; 1000 baht = US \$25). 
NHP strategy for this production facility. Seven cases are evaluated by NHP:

NC-1 engineering controls, job rotation, and the use of HPDs,

NC-2 engineering controls and job rotation,

NC-3 engineering controls and the use of HPDs,

NC-4 job rotation and the use of HPDs,

NC-5 engineering controls,

NC-6 job rotation with additional workers,

NC-7 the use of HPDs.

Initially, the database module must be visited to create a database of the facility. By clicking on the symbol in front of the data category (Figure 5), the user will see the data entry page that will allow them to enter relevant data into the NHP database.
Next, the user can visit the input module to create an NC project. While already stored data can be retrieved from the database, additional data that are necessary can be entered. Figure 6 shows a data entry page of the input module. Although there are seven cases to investigate, only one NC project needs to be created since the workplace data are the same.

Users can then visit the algorithms module to choose their preferred solution procedure (Figure 7). While both engineering controls can be chosen together, only one job rotation option can be chosen at a time. In this example, seven different combinations of NCs are defined (one for each case). Figure 8 shows an example of a report generated by the solution module for case NC-6 (job rotation with additional workers).

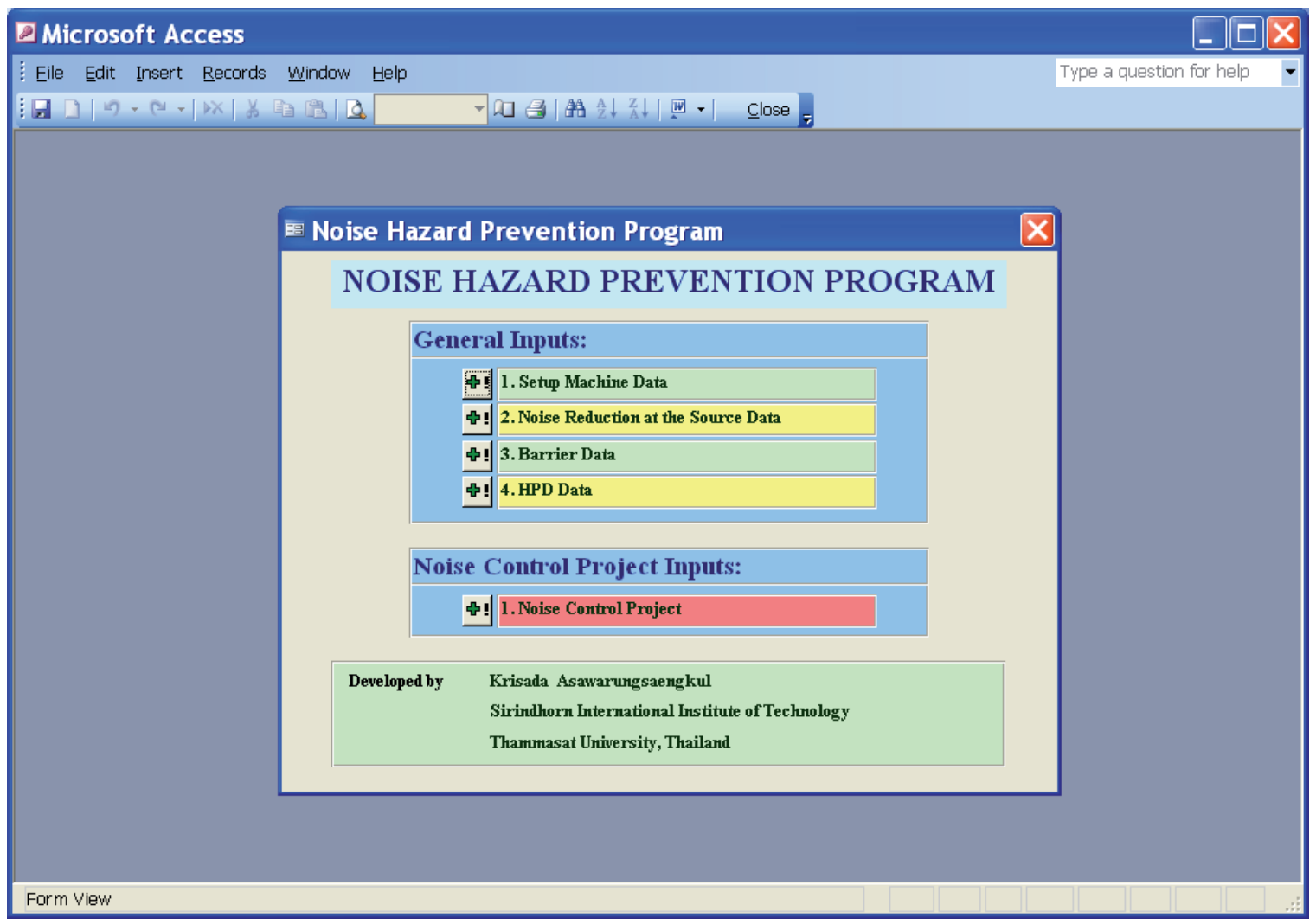

Figure 5. The main menu of the noise hazard prevention (NHP) program. Notes. HPD-hearing protection device. 


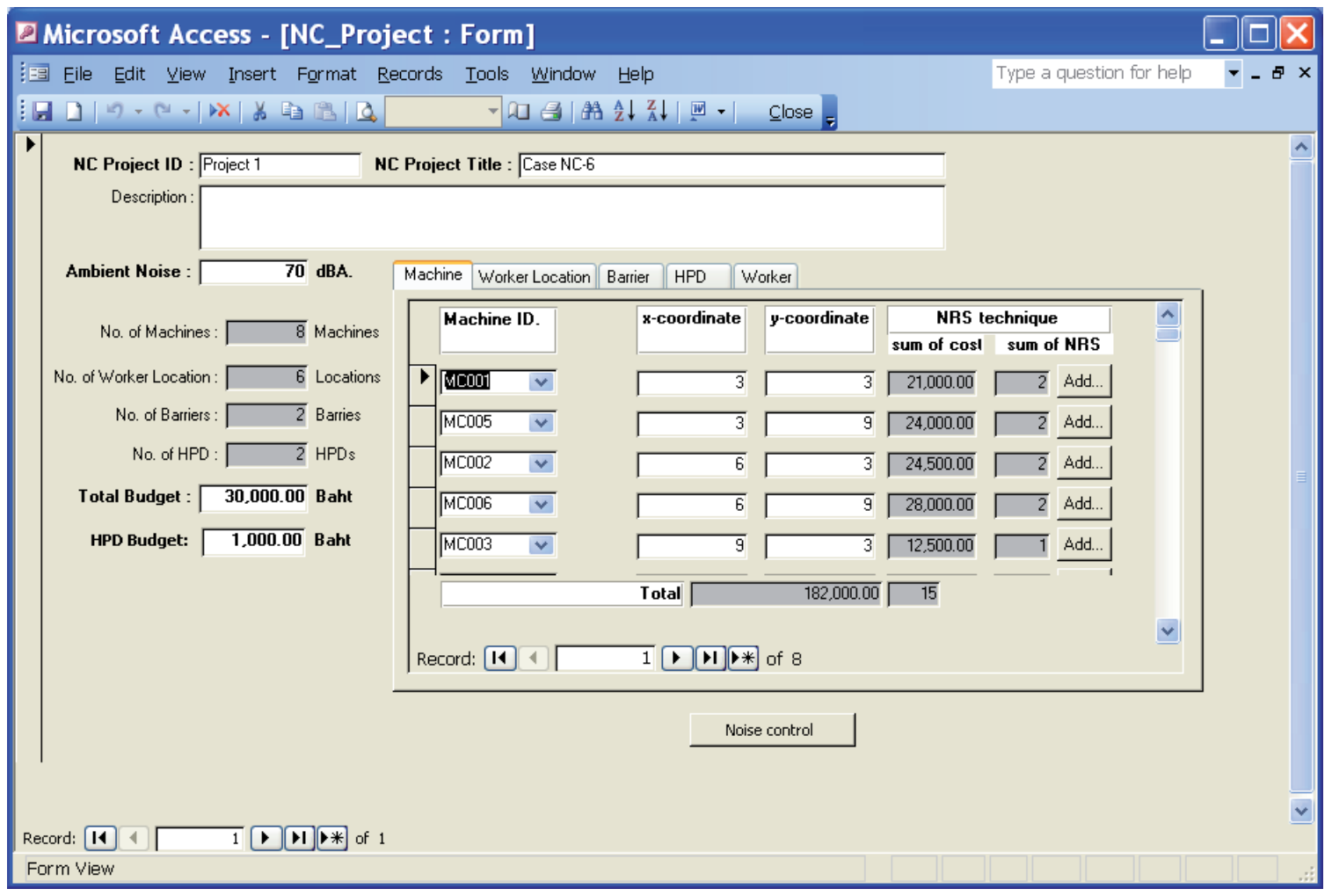

Figure 6. Data entry page of the input module of the noise hazard prevention (NHP) program. Notes. NC—noise control, ID—identification, NRS—noise reduction at the source, HPD—hearing protection device.

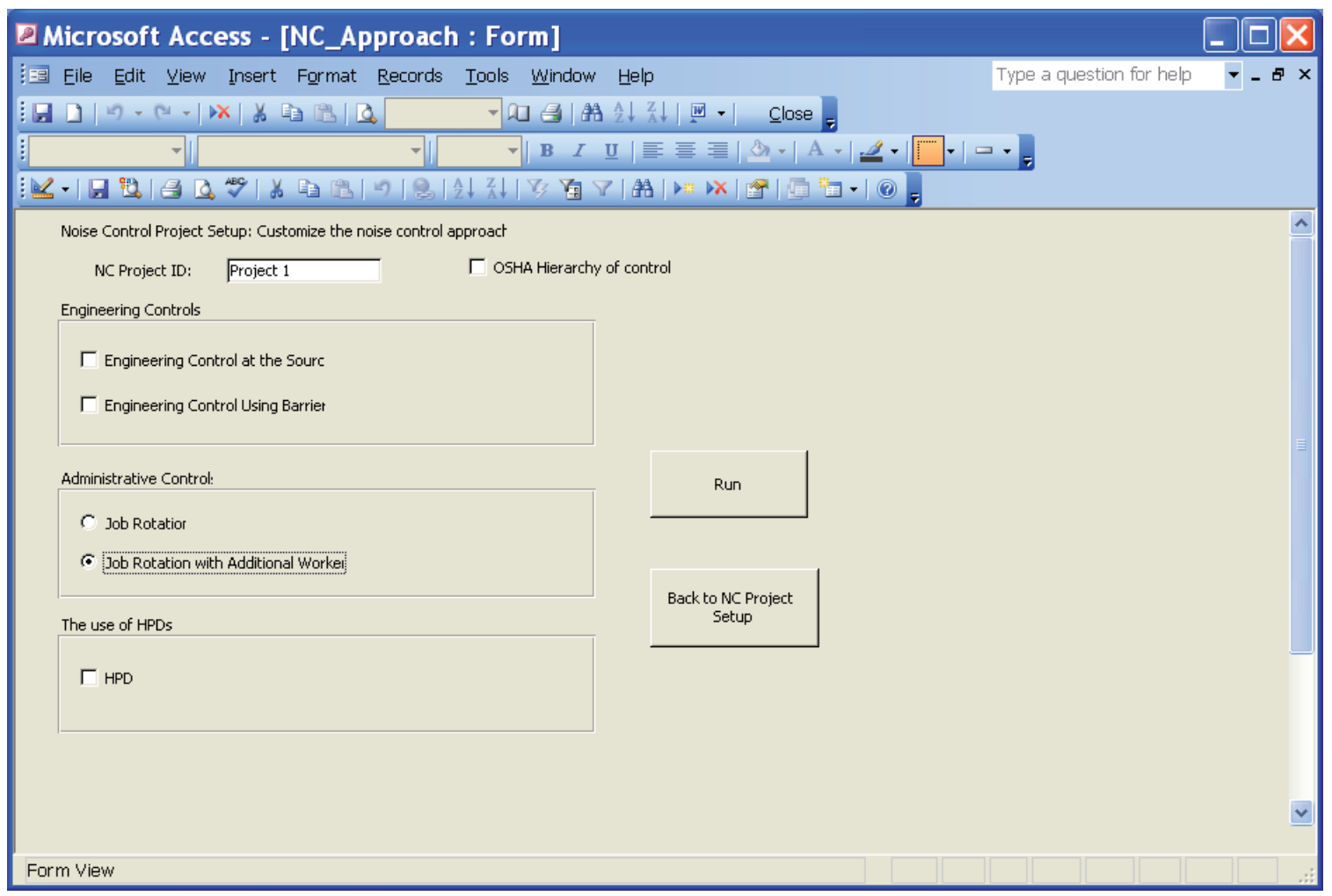

Figure 7. Data entry page of the algorithms module. Notes. NC—noise control, ID—identification, OSHA-Occupational Safety and Health Administration (USA), HPD—hearing protection device. 


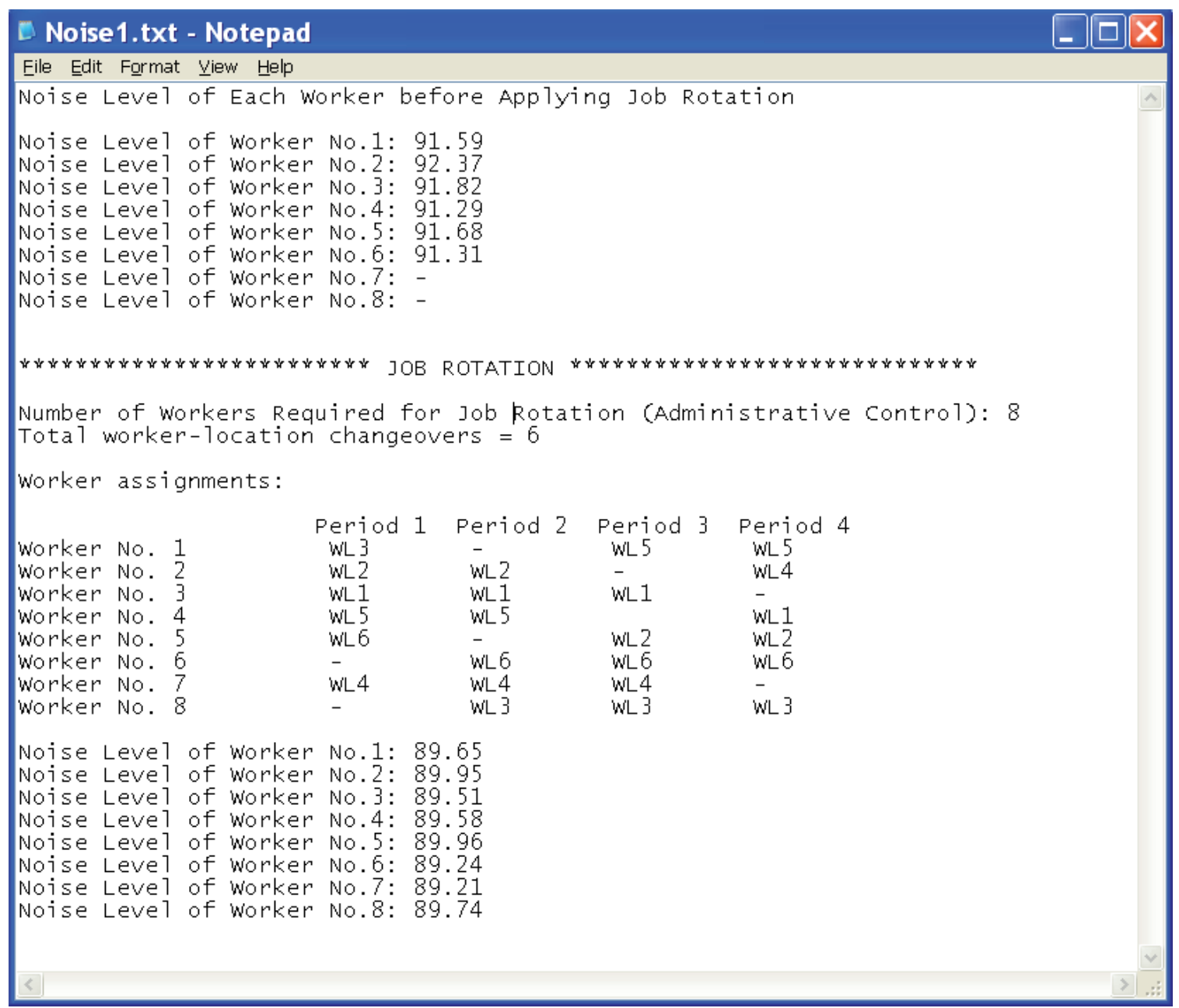

Figure 8. Solution report generated by the solution module. Notes. WL-worker location.

\section{NHP STRATEGIES}

The NHP strategy depends on workplace data, including noise condition, $\mathrm{NC}$ budget, and the solution procedure defined by the user. From the example in section 4, seven NHP strategies are generated by NHP. They can be summarized as follows.

\subsection{NHP Strategy for Case NC-1}

Case NC-1 indicates that engineering controls, job rotation (using the current workforce), and HPDs are to be applied to reduce daily noise exposures of workers. NHP recommends the following NHP strategy: (a) engineering controls-apply NRS technique 1 to machines M4, M5, and M6; (b) job rotation: implement job rotation using the current workforce (six workers).

The use of HPDs is not required. The total $\mathrm{NC}$ cost is 28500 baht (US \$712.50). The daily work assignments of the six workers are shown in Table 4. The resulting work assignments have only seven worker-location changeovers and can effectively reduce the workers' noise exposure to a safe level.

\subsection{NHP Strategy for Case NP-2}

For Case NP-2, only engineering controls and job rotation (with the current workforce) are to be applied. The recommended NHP strategy is identical to the one presented in section 5.1. The main reason for this is that with the total budget of 30000 baht (US \$750), it is sufficient to use 
TABLE 4. Daily Work Assignments of Workers and Their Daily Noise Exposures (Case NC-1)

\begin{tabular}{lcccccc}
\hline & \multicolumn{2}{c}{ Before NHP } & \multicolumn{5}{c}{ After NHP } \\
\cline { 2 - 5 } Worker & Noise Exposure (dBA) & $\mathbf{1}$ & $\mathbf{2}$ & $\mathbf{3}$ & $\mathbf{4}$ & Noise Exposure (dBA) \\
\cline { 2 - 6 } W1 & $(91.59)$ & WL2 & WL5 & WL5 & WL5 & 89.95 \\
W2 & $(92.37)$ & WL1 & WL1 & WL3 & WL3 & 88.80 \\
W3 & $(91.82)$ & WL3 & WL3 & WL1 & WL1 & 88.80 \\
W4 & $(91.29)$ & WL5 & WL6 & WL6 & WL4 & 89.88 \\
W5 & $(91.68)$ & WL5 & WL2 & WL2 & WL2 & 87.88 \\
W6 & $(91.31)$ & WL4 & WL4 & WL4 & WL6 & 88.10 \\
\hline
\end{tabular}

Notes. NHP-noise hazard prevention strategies, WL-worker location. Noise exposures shown in parentheses indicate unsafe exposures.

only engineering controls (totaling 28500 baht, or US \$712.50) and job rotation (using the current workforce) to achieve safety daily noise exposures.

\subsection{NHP Strategy for Case NP-3}

Engineering controls and the use of HPDs are the two NC approaches for case NP-3. NHP recommends an NHP strategy that costs 28800 baht (US \$720): (a) engineering controls-apply NRS technique 1 to machines M4, M5, and M6; (b) the use of HPDs - enforce the use of type-A HPD at worker locations WL1, WL5, and WL6.

When job rotation is not implemented, each worker will stay at the assigned worker location in every work period (Table 5). Although NRS technique 1 can help to reduce machine noise transmitted from machines M4, M5, and M6, noise levels at worker locations WL1, WL5, and WL6 are still excessively high. Therefore, wearing type-A HPD is enforced at these three locations.

\subsection{NHP Strategy for Case NP-4}

The NHP strategy recommended for case NP-4 is a low-cost strategy. Only job rotation (using the current workforce) and the use of HPDs are required. The strategy costs 1000 baht or US \$25 (for two type-B HPDs). The resulting work assignments have eight worker-location changeovers (Table 6). All daily noise exposures are within the permissible level. The NHP strategy is as follows: (a) job rotation-implement job rotation using the current workforce (six workers); (b) the use of HPDs-enforce the use of Type-B HPD at worker locations WL2 and WL3.

TABLE 5. Daily Work Assignments of Workers and Their Daily Noise Exposures (Case NC-3)

\begin{tabular}{lcccccc}
\hline & \multicolumn{2}{c}{ Before NHP } & \multicolumn{5}{c}{ After NHP } \\
\cline { 2 - 6 } Worker & Noise Exposure (dBA) & $\mathbf{1}$ & $\mathbf{2}$ & $\mathbf{3}$ & $\mathbf{4}$ & Noise Exposure (dBA) \\
\cline { 2 - 6 } W1 & $(91.59)$ & WL1 $^{*}$ & WL1 $^{*}$ & WL1* & WL1* & 82.97 \\
W2 & $(92.37)$ & WL2 & WL2 & WL2 & WL2 & 86.58 \\
W3 & $(91.82)$ & WL3 & WL3 & WL3 & WL3 & 85.68 \\
W4 & $(91.29)$ & WL4 & WL4 & WL4 & WL4 & 87.02 \\
W5 & $(91.68)$ & WL5 & WL5 & WL5* & WL5* & 82.80 \\
W6 & $(91.31)$ & WL6 $^{*}$ & WL6 $^{*}$ & WL6 $^{*}$ & WL6 $^{*}$ & 82.62 \\
\hline
\end{tabular}

Notes. NHP_noise hazard prevention strategies, HPD—hearing protection device, WL-worker location. Noise exposures shown in parentheses indicate unsafe exposures. Worker locations with asterisks are those where the use of HPDs is required. 
TABLE 6. Daily Work Assignments of Workers and Their Daily Noise Exposures (Case NC-4)

\begin{tabular}{lcccccc}
\hline & \multicolumn{3}{c}{ Before NHP } & \multicolumn{5}{c}{ After NHP } \\
\cline { 2 - 6 } Worker & Noise Exposure (dBA) & $\mathbf{1}$ & $\mathbf{2}$ & $\mathbf{3}$ & $\mathbf{4}$ & Noise Exposure (dBA) \\
\cline { 2 - 6 } W1 & $(91.59)$ & WL1 & WL1 & WL3 $^{*}$ & WL3* & 87.87 \\
W2 & $(92.37)$ & WL5 & WL5 & WL2 & WL4 & 89.97 \\
W3 & $(91.82)$ & WL6 & WL3* & WL5 & WL5 & 89.94 \\
W4 & $(91.29)$ & WL3* & WL6 & WL6 & WL6 & 89.71 \\
W5 & $(91.68)$ & WL4 & WL4 & WL4 & WL2* & 89.72 \\
W6 & $(91.31)$ & WL2* & WL2* & WL1 & WL1 & 87.97 \\
\hline
\end{tabular}

Notes. NHP—noise hazard prevention strategies, HPD—hearing protection device, WL-worker location. Noise exposures shown in parentheses indicate unsafe exposures. Worker locations with asterisks are those where the use of HPDs is required.

TABLE 7. Daily Work Assignments of Workers and Their Daily Noise Exposures (Case NC-5)

\begin{tabular}{lcccccc}
\hline & \multicolumn{2}{c}{ Before NHP } & \multicolumn{5}{c}{ After NHP } \\
\cline { 2 - 6 } Worker & Noise Exposure $(\mathbf{d B} \boldsymbol{A})$ & $\mathbf{1}$ & $\mathbf{2}$ & $\mathbf{3}$ & $\mathbf{4}$ & Noise Exposure (dBA) \\
\cline { 2 - 6 } W1 & $(91.59)$ & WL1 & WL1 & WL1 & WL1 & $(90.97)$ \\
W2 & $(92.37)$ & WL2 & WL2 & WL2 & WL2 & 86.58 \\
W3 & $(91.82)$ & WL3 & WL3 & WL3 & WL3 & 85.68 \\
W4 & $(91.29)$ & WL4 & WL4 & WL4 & WL4 & 87.02 \\
W5 & $(91.68)$ & WL5 & WL5 & WL5 & WL5 & $(90.80)$ \\
W6 & $(91.31)$ & WL6 & WL6 & WL6 & WL6 & $(90.62)$ \\
\hline
\end{tabular}

Notes. NHP-noise hazard prevention strategies, WL-worker location. Noise exposures shown in parentheses indicate unsafe exposures.

\subsection{NHP Strategy for Case NP-5}

Case NP-5 requires only the application of engineering controls. With the NC budget of 30000 baht (US \$750), the NHP strategy (with its total cost of 28500 baht or US $\$ 712.50$ ) can only reduce noise exposures at three worker locations (Table 7). Without job rotation or the use of HPDs, no feasible NHP strategy is effective enough to yield safety noise exposures: engineering controls-apply NRS technique 1 to machines M4, M5, and M6.

It is seen that workers $\mathrm{W} 1, \mathrm{~W} 5$, and W6 receive their daily noise exposures beyond $90 \mathrm{dBA}$. As a result of insufficient NC budget, NHP recommends that management increase the budget to 39500 baht (US \$987.50). The increased budget will allow an additional NC to be implemented. The revised NHP strategy and the resulting work assignments are shown in Table 8. The strategy costs 39500 baht (US \$987.50) to implement. Engineering controls: (a) apply NRS technique 1 to machines M1, M4, and M5; (b) apply NRS technique 2 to machine M6.

\subsection{NHP Strategy for Case NP-6}

For case NP-6, job rotation with additional workers is considered. Note that although all eight workers will be considered for job rotation, NHP will search for the minimum number of workers. Since the workplace has six worker locations, it implies that at least six workers are needed. The NHP strategy is shown below. It is a no-cost strategy since only job rotation is required. Job rotation-implement job rotation using all eight workers.

When job rotation involves more workers than worker locations, some workers will be idle in some work periods (Table 9). These idle periods help to reduce their noise exposures to a safe level. 
TABLE 8. Revised Daily Work Assignments of Workers and Their Daily Noise Exposures (Case NC-5)

\begin{tabular}{lcccccc}
\hline & \multicolumn{3}{c}{ Before NHP } & \multicolumn{5}{c}{ After NHP } \\
\cline { 2 - 6 } Worker & Noise Exposure (dBA) & $\mathbf{1}$ & $\mathbf{2}$ & $\mathbf{3}$ & $\mathbf{4}$ & Noise Exposure (dBA) \\
\cline { 2 - 6 } W1 & $(91.59)$ & WL1 & WL1 & WL1 & WL1 & 84.12 \\
W2 & $(92.37)$ & WL2 & WL1 & WL1 & WL1 & 86.58 \\
W3 & $(91.82)$ & WL3 & WL3 & WL3 & WL3 & 85.68 \\
W4 & $(91.29)$ & WL4 & WL4 & WL4 & WL4 & 87.02 \\
W5 & $(91.68)$ & WL5 & WL5 & WL5 & WL5 & 86.26 \\
W6 & $(91.31)$ & WL6 & WL6 & WL6 & WL6 & 89.98 \\
\hline
\end{tabular}

Notes. NHP_noise hazard prevention strategies, WL-worker location. Noise exposures shown in parentheses indicate unsafe exposures.

TABLE 9. Daily Work Assignments of Workers and Their Daily Noise Exposures (Case NC-6)

\begin{tabular}{lcccccc}
\hline & \multicolumn{5}{c}{ Before NHP } & \multicolumn{5}{c}{ After NHP } \\
\cline { 2 - 6 } Worker & Noise Exposure (dBA) & $\mathbf{1}$ & $\mathbf{2}$ & $\mathbf{3}$ & $\mathbf{4}$ & Noise Exposure (dBA) \\
\cline { 2 - 6 } W1 & $(91.59)$ & WL3 & - & WL5 & WL5 & 89.65 \\
W2 & $(92.37)$ & WL2 & WL2 & - & WL4 & 89.95 \\
W3 & $(91.82)$ & WL1 & WL1 & WL1 & - & 89.51 \\
W4 & $(91.29)$ & WL5 & WL5 & - & WL1 & 89.58 \\
W5 & $(91.68)$ & WL6 & - & WL2 & WL2 & 89.96 \\
W6 & $(91.31)$ & - & WL6 & WL6 & WL6 & 89.24 \\
W7 & - & WL4 & WL4 & WL4 & - & 89.21 \\
W8 & - & - & WL3 & WL3 & WL3 & 89.74 \\
\hline
\end{tabular}

Notes. NHP_noise hazard prevention strategies, WL-worker location. Noise exposures shown in parentheses indicate unsafe exposures.

TABLE 10. Daily Work Assignments of Workers and Their Daily Noise Exposures (Case NC-7)

\begin{tabular}{|c|c|c|c|c|c|c|}
\hline \multirow[b]{3}{*}{ Worker } & \multicolumn{2}{|l|}{ Before NHP } & \multicolumn{4}{|c|}{ After NHP } \\
\hline & \multirow[b]{2}{*}{ Noise Exposure (dBA) } & \multicolumn{4}{|c|}{ Work Period } & \multirow[b]{2}{*}{ Noise Exposure (dBA) } \\
\hline & & 1 & 2 & 3 & 4 & \\
\hline W1 & (91.59) & $W L 1^{*}$ & WL1* & WL1* & WL1* & 83.59 \\
\hline W2 & (92.37) & WL2* & WL2* & WL2* & WL2* & 84.37 \\
\hline W3 & (91.82) & WL3 $^{*}$ & WL3* $^{*}$ & WL3 $^{*}$ & WL3 $^{*}$ & 83.82 \\
\hline W4 & $(91.29)$ & WL4* & WL4* & WL4* & WL4* & 83.29 \\
\hline W5 & $(91.68)$ & WL5* & WL5 $^{*}$ & WL5 $^{\star}$ & WL5 $^{*}$ & 83.68 \\
\hline W6 & $(91.31)$ & WL6* & WL6 $^{*}$ & WL6 $^{*}$ & WL6 $^{*}$ & 83.31 \\
\hline
\end{tabular}

Notes. NHP_noise hazard prevention, HPD-hearing protection device, WL-worker location. Noise exposures shown in parentheses indicate unsafe exposures. Worker locations with asterisks are those where the use of HPDs is required.

\subsection{NHP Strategy for Case NP-7}

Case NP-7 requires only the use of HPDs to reduce noise exposure. When HPDs are used for NHP, they should be worn only at any worker location having its combined noise level greater than $90 \mathrm{~dB}$. Since all worker locations have their noise levels above $90 \mathrm{~dB}$, HPDs are then required at all six worker locations. For the given example, NHP recommends that six type-A HPDs be used at all six worker locations. Thus, the total NC cost is 600 baht (US \$15). Table 10 shows the resulting daily work assignments for 
the six workers. The use of HPDs - enforce the use of type-A HPD at all six worker locations.

\section{CONCLUSIONS}

The engineering approach is the most effective $\mathrm{NC}$ approach since it tackles noise hazard at its source(s). Depending on the engineering control, the reduction of the noise level can occur at one or more worker locations. One drawback of this approach is that the implementation cost tends to be expensive and the production may be interrupted. An administrative approach such as job rotation is a simple management practice that can be very effective if the workforce is flexible. However, noise hazard is still present; only exposure to hazard is reduced. The use of HPDs is a low-cost solution to NHP. Its effectiveness relies heavily on the co-operation of workers to wear HPDs.

According to OSHA's hierarchy of NC, the engineering approach is to be considered first. If engineering controls are not feasible or inadequate, an administrative approach such as job rotation should be considered next. The use of HPDs is to be used as the last resort of noise reduction. In practice, the three approaches should be applied together to achieve the objective effectively and economically. Mathematical models of some NCs are available and they can be applied to determine the optimal NHP strategy. However, for large-sized NC problems, this optimization procedure is not practical.

The proposed DSS for NHP is an alternative means to the workplace noise problem. It applies the concept of DSSs to generate effective NHP strategies, along with the required total $\mathrm{NC}$ cost and the resulting daily noise exposures of all workers. Through its four modules, the user can create an NC project; input workplace, machine, NCs, and HPD data; choose a preferred solution procedure; and view a detailed NHP solution report.

From the given example, an NC project is created. Then, it is evaluated using seven different combinations of NCs. NHP is utilized to generate effective NHP strategies, with all resulting daily noise exposures not exceeding the permissible level. For case NC-5 in which only engineering controls are to be applied, the NC budget of 30000 baht (US \$750) is found to be insufficient. Nevertheless, by increasing the budget to 39500 baht (US \$987.50), it is possible to find an NHP strategy that is effective. In practice, management can use NHP to generate NHP strategies based on different NC budget levels and solution procedures. Then, the most preferred strategy can be chosen and implemented.

NHP helps to make NHP practical, economical, and effective. The recommended NHP strategy can be presented in a quantitative manner, making the implementation of the strategy convenient. Moreover, the effectiveness of the NHP strategy can be validated by the safety daily noise exposures of all workers that are computed by NHP.

\section{REFERENCES}

1. Harris CM. Handbook of noise control. New York, NY, USA: McGraw-Hill; 1979.

2. Beranek LL, Vér IL. Noise and vibration control engineering, principles and applications. New York, NY, USA: Wiley; 1992.

3. Cheremisinoff PN. Industrial noise control. Englewood Cliffs, NJ, USA: Prentice Hall; 1993.

4. Ridley J. Safety at work. Oxford, UK: Butterworth-Heinemann; 1994.

5. Wilson CE. Noise control, measurement, analysis, and control of sound and vibration. Malabar, FL, USA: Krieger; 1994.

6. Bies DA, Hansen $\mathrm{CH}$. Engineering noise control, theory and practice. London, UK: Chapman \& Hall; 1996.

7. Nanthavanij S, Yenradee P. Analytical determination of worker assignment with workplace noise consideration. In: Dessouky MI, editor. C\&IE 1999: Proceedings of the 25th International Conference on Computers and Industrial Engineering. New Orleans, LO, USA: Computers and Industrial Engineering; 1999. p. 411-4.

8. Nanthavanij S, Kullpattaranirun T. A genetic algorithm approach to determine minimax work assignments. Int $\mathrm{J}$ Ind Eng-Theory. 2001;8;176-85. 
9. Kullpattaranirun T, Nanthavanij S. A heuristic genetic algorithm for solving complex safety-based work assignment problems. Int J Ind Eng-Theory. 2005; 12;43-55.

10. Yaoyuenyong K, Nanthavanij S. A modified LPT swap heuristic for solving large minimax work assignment problems. Ind Eng Manage Syst. 2003;2(2):121-30.

11. Nanthavanij S, Yenradee P. Minimum number of workers and their daily work assignment to operate $\mathrm{n}$ noisy machines based on permissible noise exposure limit. In: Chern MS, Sheu DD, Wang MJ, editors. IJIE 2000: Proceeding of the 5th Annual Conference on Industrial EngineeringTheory, Applications and Practice [CDROM]. Hsinchu, Taiwan; Industrial Engineering-Theory, Applications and Practice; 2000.

12. Behar A, Kunov H. Insertion loss from using double protection. Appl Acoust. 1999;57(4):375-85.

13. Crabtree RB, Behar A. Measurement of hearing protector insertion loss at ultrasonic frequencies. Appl Acoust. 2000;59(3): 287-99.

14. Birch RS, Gerges SN, Vergara EF. Design of a pulse generator and shock tube for measuring hearing protector attenuation of high amplitude impulsive noise. Appl Acoust. 2003;64(3):269-86.

15. Buchweiller JP, Mayer A, Klein R, Iotti JM, Kusy A, Reinert D, Christ E. Safety of electronic circuits integrated into personal protective equipment (PPE). Safety Sci. 2003;41(5):395-408.

16. Feeney RJ. Why is there resistance to wearing protective equipment at work? Possible strategies for overcoming this. J Occup Accid. 1986;8(3):207-13.

17. Occupational Safety and Health Administration. Occupational noise exposure: hearing conservation amendment. Fed Reg. 1983;48:9738-83.

18. Sanders MS, McCormick EJ. Human factors in engineering and design. New York, NY, USA: McGraw-Hill; 1993.

19. Sutton P. Process plant noise: evaluation and control. Appl Acoust. 1976;9(1):17-33.
20. Asawarungsaengkul K, Nanthavanij S. Design of optimal noise hazard control strategy with budget constraint. International Journal of Occupational Safety and Ergonomics (JOSE). 2006;12(4):355-67.

21. Young LF. Decision support systems for workers: a bridge to advancing productivity. Inform Manage. 1989;16:131-40.

22. Ntuen CA, Winchester WW, Chestnut J, Park, EH. PASIM: a spreadsheet-based decision support system for performance analysis of production workers. Comput Ind Eng. 1994;27(1-4):193-6.

23. Jaturanonda $C, \quad$ Nanthavanij $S$, Chalidabhongse J. Analytic-based decision support system for employee-job assignment based on competency and job preference (working paper No. MT-0503). Pathumthani, Thailand: Sirindhorn International Institute of Technology, Thammasat University; 2005.

24. Peckham RJ, Haastrup P, Otway H. A computer-based system for risk management. Decision Support Syst. 1998;4(4): 481-9.

25. Gheorghe AV, Mock R, Kröger W. Risk assessment of regional systems. Reliability Eng Syst Saf. 2000;70:141-56.

26. Hanss EJ. Are decision support systems applicable to engineering management? Eng Manage Int. 1984;2(4):243-50.

27. Parker S, Malstrom EM, Irwin LM, DuCote G. A decision support system for personnel scheduling in a manufacturing environment. Comput Ind Eng. 1994;27(1-4):185-8.

28. Padillo JM, Ingalls R, Brown S. A strategic decision support system for supply network design and management in the semiconductor industry. Comput Ind Eng. 1995;29(1-4):443-7.

29. Chaudhry SS, Salchenberger L, Beheshtian M. A small business inventory DSS: design, development, and implementation issues. Comput Op Res. 1996;23(1):63-72.

30. Kim SH, Lee KK. An optimization-based decision support system for ship scheduling. Comput Ind Eng. 1997;33(3-4):689-92.

31. Chien CF, Deng JF. A container packing support system for determining and visualizing container packing patterns. Decision Support Systems. 2004;37:23-34. 
32. Kengpol A. Design of a decision support system to evaluate the investment in a new distribution centre. Int J Prod Econ. 2004; 90:59-70.

33. Olishifski JB, Standard JJ. Industrial noise. In: Plog BA, editor. Fundamentals of industrial hygiene. 3rd ed. Itasca, IL, USA: National Safety Council; 1998.

34. Asfahl C Ray. Industrial safety and health management. 4th ed. Upper Saddle River, NJ, USA: Prentice Hall; 1999.

35. Goetsch DL. Occupational safety and health for technologists, engineers, and managers. 5th ed. Upper Saddle River, NJ, USA: Prentice Hall; 2005.
36. Asawarungsaengkul $\mathrm{K}$, Nanthavanij $\mathrm{S}$. Analytical procedures for designing an optimal noise hazard prevention program. Ind Eng Manage Syst. 2005;4(2):165-75.

37. Asawarungsaengkul K, Nanthavanij S. A genetic algorithm approach to the selection of engineering controls for optimal noise reduction. ScienceAsia. 2007;33:89-101.

38. Yaoyuenyong S, Nanthavanij S. Hybrid procedure to determine optimal workforce without noise hazard exposure. Comput Ind Eng. 2006;51:743-64.

39. Asawarungsaengkul $\mathrm{K}$, Nanthavanij $\mathrm{S}$. Heuristic GA for workforce scheduling with minimum total worker-location changeover (working paper No. MT0605). Pathumthani, Thailand: Sirindhorn International Institute of Technology, Thammasat University; 2006. 